\title{
Experimental Research of the Influence of Bedload Sediment Heterogeneity on Length, Height and Shifting Velocity of Growing Bed Configuration
}

\author{
Nazir Ikramov*, Takhir Majidov \\ Tashkent, Uzbekistan \\ Email address: \\ Ikramov-1978@mail.ru (N. Ikramov), suvchi2001@yahoo.com (T. Majidov) \\ ${ }^{*}$ Corresponding author
}

Department of Usage of Water Energy and Pumping Stations, Tashkent Institute of Irrigation and Agricultural Mechanization Engineers,

\section{To cite this article:}

Nazir Ikramov, Takhir Majidov. Experimental Research of the Influence of Bedload Sediment Heterogeneity on Length, Height and Shifting Velocity of Growing Bed Configuration. Industrial Engineering. Vol. 4, No. 2, 2020, pp. 43-49. doi: 10.11648/j.ie.20200402.13

Received: October 9, 2019; Accepted: October 26, 2019; Published: September 3, 2020

\begin{abstract}
In the natural current of water, the growing bed movement leads to a reduction of reservoir volume and canal cross-section area, filling by forebay of pump station and hydroelectric station pressure basins with sediment. This leads to abrasive wear of pumps, water turbines, and pressure pipelines, as well as other negative consequences. In many countries, rivers come laden with a large amount of sediment and enormous costs. At determining of sediment discharge it is important values of height and movement velocity of bed ridges. The determination of these values is based on experimental studies was not taken into account the heterogeneity of sediment with different fractions. For this reason, the calculated values according to obtained formulas have large discrepancies with field data. To eliminate these discrepancies, experimental studies were conducted using six types of fractions with the same weighted average diameter. Based on of laboratory data diagrams and interrelation were obtained for ridge length, height and movement velocity from sediment hydraulic and geometric sizes.
\end{abstract}

Keywords: Bedload Sediment Heterogeneous, Flow Velocity, Ridge Length, Height and Movement Velocity

\section{Introduction}

Periodical structures form on an erodible surface when it interacts with air or water flow. Such periodical structures can be seen on the bottom of all waterways and reservoirs, on the snow surface, in hydro and pneumatic transport pipes. Data about the wavelike movement of Karakum sands in shape of pocks, ridges, and dunes are given in work [1]. Formation of ripples are observed even in the Pacific ocean under the action of deep current. Movement disperses medium under influence of turbulent flow in the form of periodical structures yield a huge loss to the humanity, since it deforms river and man-made waterway channels and carries sand and snow into the sites of national economy and etc. This has made people fight against the negative consequences of this phenomenon since olden times.

For the first time, they have started to study sediment movement in China in the $15^{\text {th }}$ Century. Channel control works were required for rivers in China (for instance, Huang
He), which carry a huge amount of sediment.

Later, with the development of navigation, the science about sediment movement has started to develop in Europe. First Du Bua and later Dikon have carried out their research in this area $[2,3]$. DuBua observed bedload form creation and movement in laboratory conditions, and Baumgarten observed bedload form movement in field conditions for the first time and measured the parameters in Garonne river.

It is impossible to solve the problem, related to the formation and realization of bedload periodical structural forms in turbulent flow by analytical methods, since the process depends on many factors [4-7]. In present, such problems are solved by laboratory research and the accuracy of obtained results are estimated with field observations [813]. Discrepancy in estimated and observed parameters of ridges is mainly related to bedload structure variation in space and time, imperfection of measuring technology and methods. As a result of laboratory and field research until now huge amount of theoretical and empirical formulas have 
been obtained, which determine the connection of bedload form parameters to flow and sediment characteristics [14-18, $1,8,9]$. The range of new tasks has been revealed, and their solution is yet to be obtained.

After Dikon and Engels's experimental research, in 1914 G. Jilbert and Murphy's experimental work came out [19]. B. F. Snishenko, Z. D. Kopaliani, T. Sh. Majidov, D. M. Kondep, A. B. Gray, D. Saymons, E. Richardson, P. Sanghal, B. Singh, Jalin M. S., Hassan W. N. M., Bagnold, R. A., Hall Philip and others have also brought in a huge contribution in studying bedload sediment movement [20-31, 1, 8, 14, 15].

All the above listed works lack consideration of the impact of sediment natural composition change on the length, height, and velocity of ridge movement, therefore we decided to conduct additional research in this area.

\section{Materials and Methods}

\subsection{The goal and Research Tasks}

The goal of the research is to estimate the impact of the various types of heterogeneous sediment of constant size on the length, height, and velocity of channel ridge form movement.

The following research tasks were set:

1. Improving methods for accounting varieties of heterogeneous soils.

2. Checking the applicability for the coefficient of heterogeneity of mixtures as $\varepsilon=d_{m} / d_{i}$, involving the existing data on grain-size distribution of bedload heterogeneous sediment.

3. Set up the following relationship of flow characteristics and ridge parameters with the coefficient of mixture heterogeneity:

$$
\begin{gathered}
\mathrm{H}, \mathrm{I}, \vartheta, \vartheta_{0}, \mathrm{q}_{\mathrm{r}}=\mathrm{f}\left(\varepsilon=\mathrm{d}_{\mathrm{m}} / \mathrm{d}_{\mathrm{i}}\right) \\
\mathrm{h}_{\mathrm{r}}, \mathrm{l}_{\mathrm{r}}, \mathrm{C}_{\mathrm{r}}=\mathrm{f}\left(\varepsilon=\mathrm{d}_{\mathrm{m}} / \mathrm{d}_{\mathrm{i}}\right)
\end{gathered}
$$

4. Determining the impact of sediment mean size, composition and flow hydraulic characteristics of ridge parameters:

$$
h_{\mathrm{r}}, l_{\mathrm{r}}, C_{\mathrm{r}}=\mathrm{f}\left(\mathrm{H}, \vartheta, \mathrm{Q}, \mathrm{I}, \vartheta / \vartheta_{0}, \mathrm{~d}_{\mathrm{m}}, d_{\max }, \mathrm{d}_{\mathrm{m}} / \mathrm{d}_{\mathrm{i}}\right)
$$

where: $\mathrm{d}_{\mathrm{m}}-$ mean sediment diameter;

$d_{\max }$ - maximum sediment diameter;

$\mathrm{d}_{\mathrm{i}}-$ particle sizes with corresponding probability $(i=5,10$, $15,25,35,50,60,65,70,75,85,90,95)$;

$\vartheta$ and $\vartheta_{0}-$ mean and eroding flow velocity;

$H$ - mean flow depth;

$I$ - water surface slope;

$\mathrm{q}_{\mathrm{T}}$ - bedload sediment discharge;

$\varepsilon$ - coefficient of sediment heterogeneity;

$h_{\mathrm{r}}, l_{\mathrm{r}}, C_{\mathrm{r}}$ - height, length and velocity of ridge movement, accordingly.

Since it is difficult to estimate the impact of heterogeneity of various types of natural sediment on the process of bedload ridge formation and movement in field conditions, main experiments were conducted in laboratory conditions (Table 1, Figure 1). Experimental research was conducted on hydraulic channel in the laboratory, field observations of ridge movement for various sediment composition were done

\begin{tabular}{|c|c|c|c|c|c|c|c|c|c|c|c|c|}
\hline \multirow{2}{*}{ No. } & \multirow{2}{*}{ Type of sediment } & \multicolumn{9}{|c|}{ Grain-size distribution in \% mass, for particle size in $\mathrm{mm}$} & \multirow{2}{*}{$\begin{array}{l}d_{m}, \\
M M\end{array}$} & \multirow{2}{*}{$\varepsilon=\frac{d_{m}}{d_{50}}$} \\
\hline & & $10 \div 7$ & $7 \div 5$ & $5 \div 3$ & $3 \div 2$ & $2 \div 1$ & $1 \div 0.5$ & $0.5 \div 0.25$ & $0.25 \div 0.1$ & $<0.1$ & & \\
\hline 1 & Edge fractioned & - & - & 56.75 & 2.25 & 2.75 & 4.5 & 14.9 & 14.25 & 4.6 & 2.49 & 0.83 \\
\hline 2 & Small fractioned & 9.5 & 8.5 & 8.75 & 13.75 & 22.25 & 14.75 & 8.75 & 9.25 & 4.5 & 2.51 & 2.24 \\
\hline 3 & Large fractioned & - & - & 36.5 & 27 & 18 & 11.5 & 5.07 & 1.31 & 0.62 & 2.53 & 1.24 \\
\hline 4 & Evenly fractioned & 11.1 & 10.1 & 10.1 & 11.1 & 11.1 & 11.1 & 11.1 & 12.1 & 12.2 & 2.51 & 2.8 \\
\hline 5 & Mean fractioned & - & 14,4 & 14.8 & 15.3 & 32.7 & 18.6 & 2.2 & 1.25 & 0.75 & 2.48 & 1.88 \\
\hline 6 & Homogeneous & - & - & - & 100 & - & - & - & - & - & 2.50 & 1.0 \\
\hline
\end{tabular}
on canals and rivers of the republic.

Table 1. Grain-size distribution of artificially made sediment.

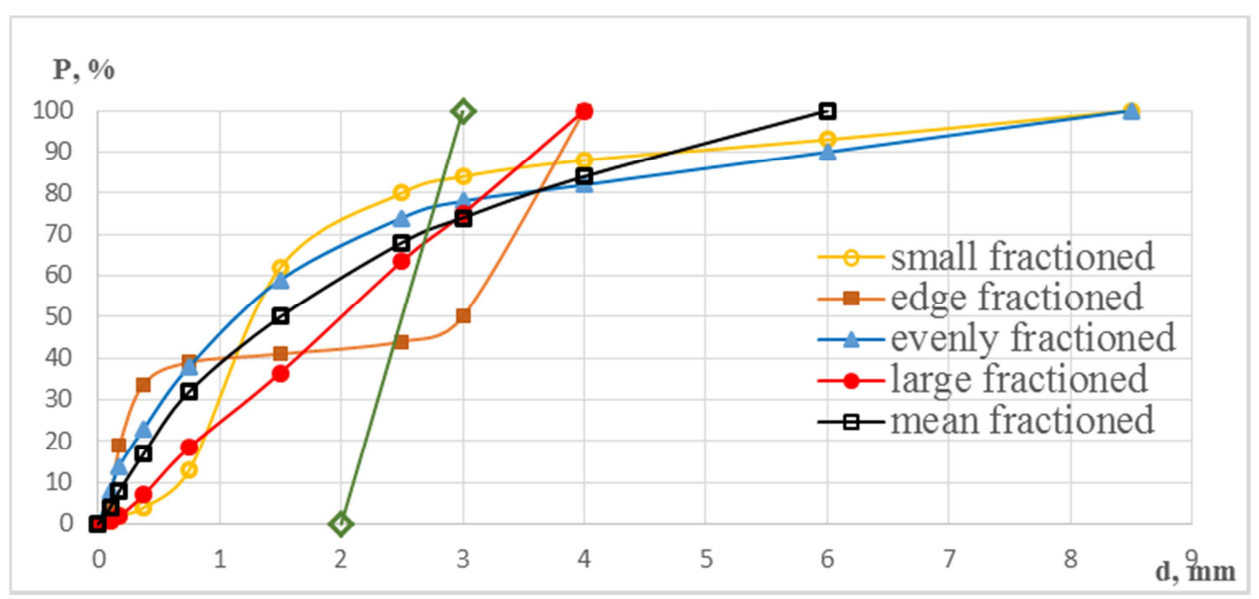

Figure 1. Grain-size distribution of experimented mixtures. 


\subsection{Laboratory Experiments}

Experimental studies were carried out in the channel laboratory of the Research Institute for Irrigation and water problems in the hydraulic tray (Figure 2). The hydraulic tray has the following dimensions: length is $10.0 \mathrm{~m}$, width is 0.24 $\mathrm{m}$ and the height of the sides is $0.60 \mathrm{~m}$. Water is supplied from the pool by a centrifugal pump to the head, and then to a water receiving tank with a triangular weir with a thin wall, between a pipe with a diameter of $0.40 \mathrm{~m}$ and through a metal mesh-damper on the tray.

At the end of the tray there is a water discharge plate for regulating the depth of water, the position of which is set using a knob and a millimeter scale, and a concrete threshold, $0.15 \mathrm{~m}$ high to prevent erosion of the final section. The rail is mounted on the tray in a horizontal position for moving the microeholot cart and tester.

Measurement of hydraulic flow elements was carried out in four working sections, located at a distance from the beginning of the tray, respectively: $2.0 \mathrm{~m} ; 4.0 \mathrm{~m} ; 6.0 \mathrm{~m}$ and $8.0 \mathrm{~m}$.

Experimental studies included six series of main experiments. Each series consisted of ten to fifteen experiments, with water consumption $-\mathrm{Q}=5,10,15,20 \mathrm{l} / \mathrm{s}$. With a constant flow rate of water, only the amount of solid flow rate was changed (carried out from one to six experiments). A total of 81 experiments were performed.

To reproduce natural flows, flowing on eroded channels and transporting bottom and suspended sediments in the laboratory, there is a need for a uniform supply of experimental material to the model. In many cases, the flow of sediment is done manually: in portions, after a certain time interval. Firstly, it is very laborious, requires additional labor, and secondly, the continuity of the mechanism of natural mixing of sediment with the flow is violated. This leads to a distortion of the results, i.e. characteristics of the flow and channel of the process under investigation on eroded models. In order to improve the flow of sediment on the experimental unit, a disk-scraper type dispenser was designed [20]. The dispenser is designed for a uniform supply of dry and raw experimental material to the channel models in a wide range of their composition and size.

Experiments with each water flow began with the smallest amount of sediment. In subsequent experiments, only the amount of solid flow rate increased, the water flow rate and the position of the shield at the end of the tray remained unchanged until the end of the experiment.

Before the start of the experiment, the sediment of this mixture lay $0.15 \mathrm{~m}$ under a certain gradient at the bottom of the tray $-I_{0}$. Before the experiment, the material was kept under water for 12-24 hours. In order to avoid erosion of the bottom, at the beginning of each experiment, the tray was filled with water to a depth of $0.30-0.40 \mathrm{~m}$ from the downstream, with the shield closed. The water flow was set and a uniform flow regime was set on the tray, at which bedding began, i.e. average flow rate was close to nonblurring $\vartheta_{\mathrm{av}}=\vartheta_{0}$, after which the flow of sediment to the flow in the initial part of the tray began to flow. After some time, in the initial part the bottom mark changed and the flow velocity increased. The resulting protrusion of the bottom is a single ridge, began to move downstream and passed the entire width of the tray. After the passage of this wave in the tray, a new bottom slope and a free surface of water were established. When the state of hydrodynamic equilibrium was established, i.e. the volume of sediment discharge captured was equal to that supplied and the slope of the eroded bottom remained on average constant, measurements of the bottom relief with a micro-echo sounder began, after which the experiments were stopped. To study the development of dynamic and geometric dimensions of the ridges, echo sounding was performed without stopping the experiments. The speed of movement of the trolley was close to the flow rate.
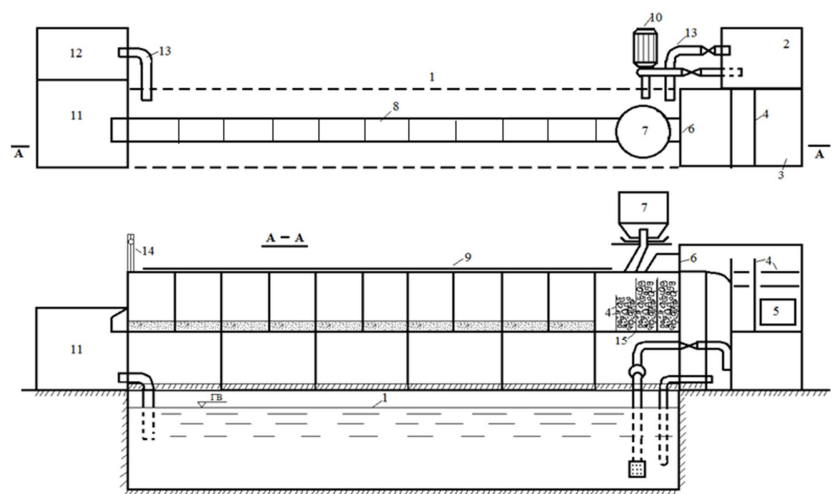

Figure 2. Scheme of a flat glazed experimental unit.

1-main pool; 2-main tank; 3-water intake tank; 4-mesh damper; 5-pipe connecting; 6-weir; 7-dispenser; 8-tray; 9-rail; 10-centrifugal pump; 11,12pool sump; 13 return pipes; 14-regulating shield; 15- shavings absorbers.

The speed of movement determined by echoing was checked by the results of visual observations. In order to avoid errors when measuring the sediment discharge in a volumetric way, taking into account the pulsating nature of the sediment movement, sediment received in the sand trap during the passage of 3-4 bottom waves were taken.

After the termination of the experiment, water from the tray was gradually released without disturbing the state of the bottom structures. The measurements of the parameters of the bottom forms, as well as their photographs, were carried out.

To study the distribution of particle size on the length of the bottom of forms in several places sampled. In order to study the sedimentation in the formation of waves, samples were taken, and on the body is thicker bottom structures. The average flow velocity was determined by the average depth of the flow, taken over the crest of structural forms. When studying the kinematics of the flow, the velocity was measured simultaneously by several microwheels.

In subsequent experiments of this series, the bottom slope remained unchanged, as it was at the end of the previous experiment, only the amount of sediment supplied increased. With the transition to another series of experiments, the bottom slope was established again [32]. 


\section{Results and Discussion}

\subsection{Ridge Length}

Ridge length is one of the important ridge form characteristics. Almost in all the theoretical works, related to the study of ridge formation mechanisms, ridge form lengths are studied. Since one of the goals of our research was to set the connection of ridge length of various sediment composition with constant mean particle size and relative flow velocity, from the obtained experimental data we created graphical relationships of $-l_{r} / d=f\left(\vartheta / \vartheta_{0}\right)$ (Figure 3).

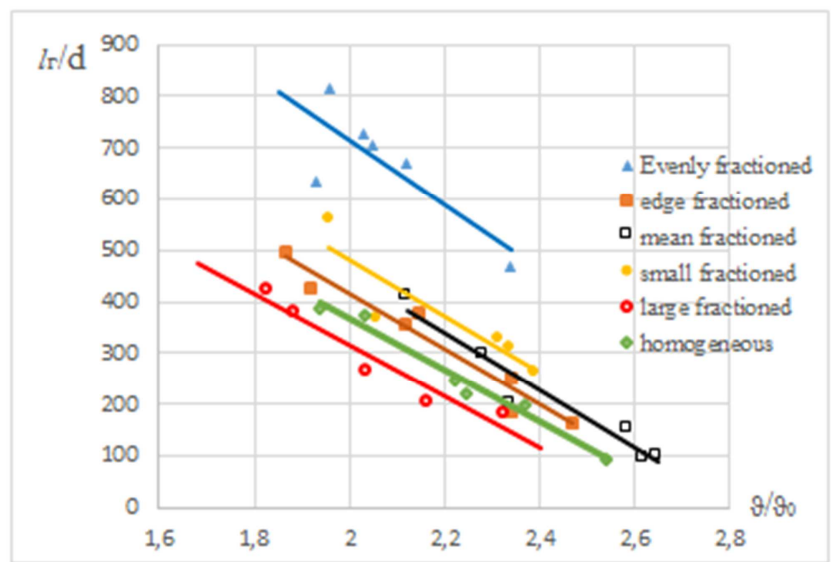

Figure 3. Plot of ridge length and sediment composition to the relative flow velocity.

The analysis of the obtained graphs showed that with an increase in flow rate, the influence of particle size on the height of the ridges increases [32]. If the value $\vartheta / \vartheta_{0}=2.2 \div 2.4$ ridges have a maximum height. With a further increase in the ratio of speeds $\left(\vartheta / \vartheta_{0}>2.4\right)$ the height of the ridges decreases. At the same time, the influence of sediment size also decreases. For values - $\vartheta / \vartheta_{0}=2.3 \div 2.5$ the influence of sediment size on the height of the ridges is insignificant. The following design formula was obtained on the basis of analytic and graphical relationship with accuracy of $0.8 \div 0.95$ :

$$
\frac{l_{r}}{d}=-K_{l}\left(\frac{\vartheta}{\vartheta_{0}}\right)+K_{d}
$$

where: $K_{l}$ - the coefficient of proportionality for the i-th composition, which, on the basis of the obtained graphical dependence (Figure 4), is determined by the following formula:

$$
K_{l}=49.9 \varepsilon^{2}-127.4 \varepsilon+594
$$

$K_{d}$ the coefficient depending on the heterogeneity of the ridge, based on the obtained graphical dependencies (Figure $5)$, is determined by the formula:

$$
\mathrm{K}_{d}=262.9 \varepsilon^{2}-682.4 \varepsilon+1824
$$

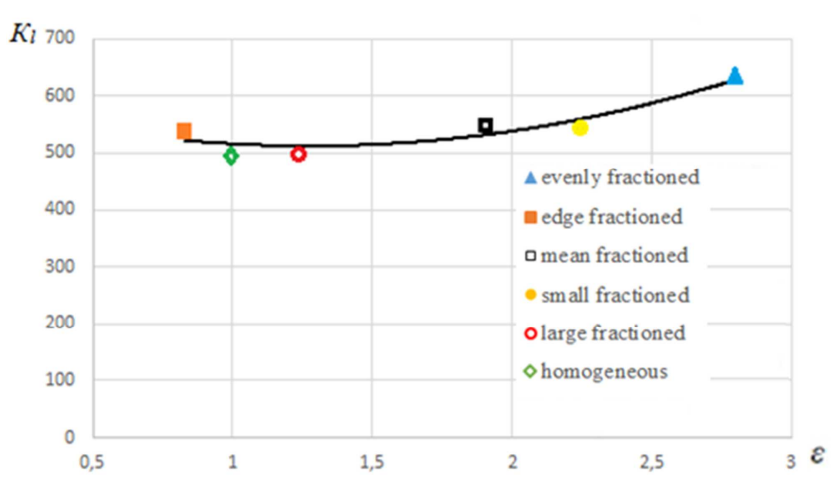

Figure 4. Graph of the dependence of the coefficient $K_{l}$ on the heterogeneity of sediment.

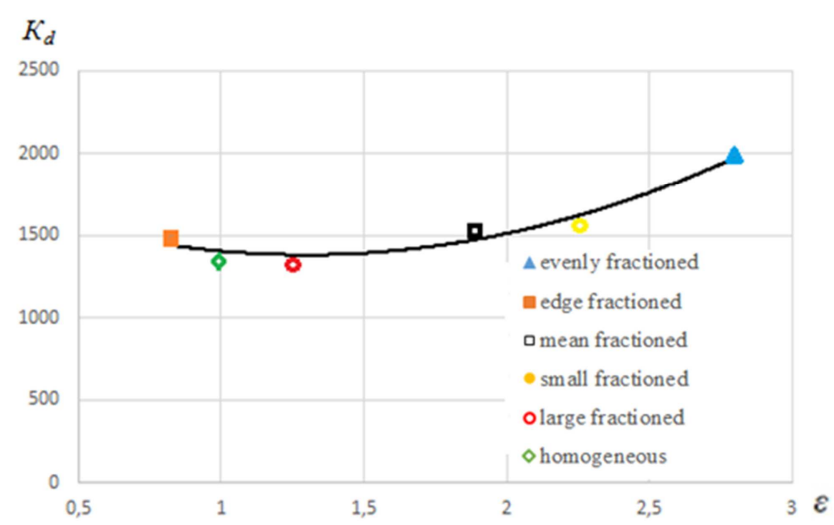

Figure 5. The graph of the dependence of the coefficient $K_{d}$ from the heterogeneity of sediment.

Substituting (4), (5), (3) we get the following dependency:

$$
\begin{gathered}
\frac{l_{r}}{d}=-\left(49.9 \varepsilon^{2}-127.4 \varepsilon+594\right)\left(\frac{\vartheta}{\vartheta_{0}}\right)+262.9 \varepsilon^{2}- \\
682.4 \varepsilon+1824
\end{gathered}
$$

here:

$$
\begin{gathered}
l_{r}=d\left(-\left(49.9 \varepsilon^{2}-127.4 \varepsilon+594\right)\left(\frac{\vartheta}{\vartheta_{0}}\right)+262.9 \varepsilon^{2}-\right. \\
682.4 \varepsilon+1824)
\end{gathered}
$$

\subsection{Ridge Height}

Determining ridge height in channel flow is necessary for estimating bed roughness in determining channel hydraulic resistance, bedload sediment discharge and channel deformation calculations, also for setting threshold height in water intake structures, installation depth for pump station exhaust pipes and etc.

In order to set the connection of ridge height of various sediment composition with constant mean particle size and relative flow velocity, from the obtained experimental data we created graphical relationships of $-h_{r} / d=f\left(\vartheta / \vartheta_{0}\right)$ (Figure 6). 


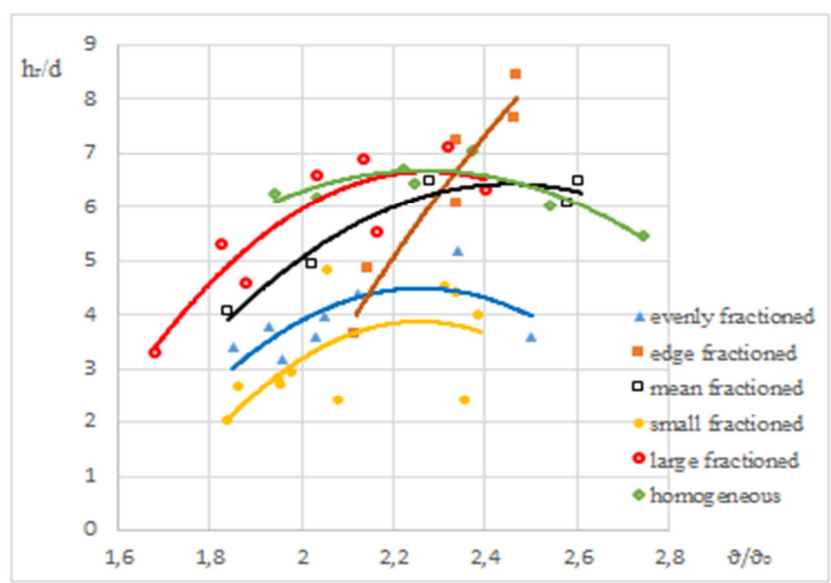

Figure 6. Plot of ridge height and sediment composition to the relative flow velocity.

Data analysis of the influence of particle size of sediment on the height of the ridges, depending on $\vartheta / \vartheta_{0^{-}} h_{r}=f\left(d, \vartheta / \vartheta_{0}\right)$ show fine fraction material $\left(\mathrm{d}_{\mathrm{i}}=0.1 \div 10.0 \mathrm{~mm} ; \mathrm{d}_{\mathrm{m}}=2.51 \mathrm{~mm}\right)$ to experimental data with large fractional material $\left(\mathrm{d}_{\mathrm{i}}=0.1 \div 5.0 \mathrm{~mm} ; \mathrm{d}_{\mathrm{m}}=2.53 \mathrm{~mm}\right)$, height of ridges with equal values $-\vartheta / \vartheta_{0}$, tends to decrease [32]. With increasing flow rate, the influence of particle size on the height of the ridges increases. If $\vartheta / \vartheta_{0}=2.2 \div 2.4$ ridges have a maximum height. With a further increase in the ratio of speeds $\left(\vartheta / \vartheta_{0}>2.4\right)$ ridge height decreases. At the same time, the influence of sediment size also decreases. At values $-\vartheta / \vartheta_{0}=2.3 \div 2.5$ the influence of sediment size on the height of the ridges is insignificant.

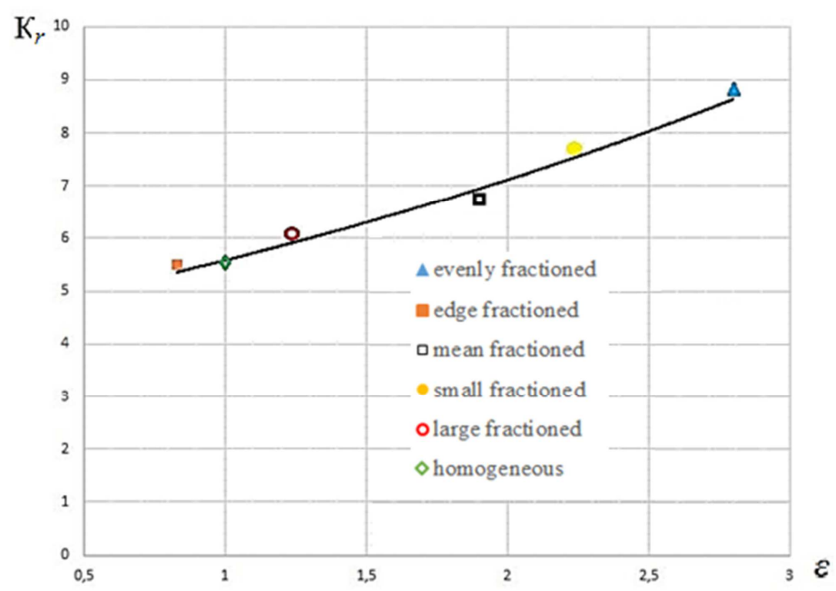

Figure 7. Graph of the dependence of the coefficient $K_{r}$ on the heterogeneity of sediment.

The following design formula was obtained on the basis of the analysis of the graphical relationship with accuracy of $0.7 \div 0.9$ :

$$
\frac{h_{r}}{d}=-\mathrm{K}_{r} \cdot\left(\frac{\vartheta}{\vartheta_{0}}\right)^{2}+\mathrm{K}_{n} \cdot\left(\frac{\vartheta}{\vartheta_{0}}-1.1\right)
$$

where: $\mathrm{K}_{\mathrm{r}}$ - the proportionality factor for the i-th composition, which, on the basis of the graphical dependence obtained (Figure 7), is determined by the following formula:

$$
K_{r}=4.38 \cdot e^{0.23 \cdot \varepsilon}
$$

$K_{\mathrm{n}}$ - the coefficient depending on the heterogeneity of the ridge, based on the resulting graphical dependence (Figure 8), is determined by the formula:

$$
\mathrm{K}_{n}=-9.2 \varepsilon^{2}+35.8 \varepsilon+12.7
$$

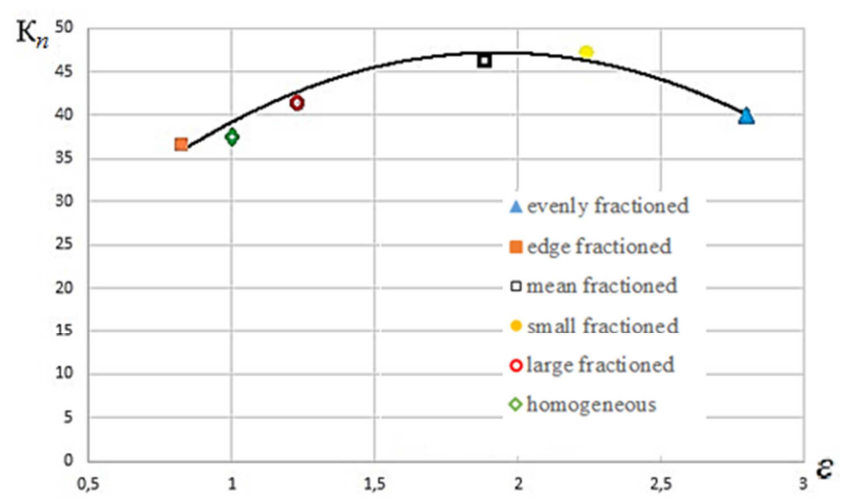

Figure 8. Graph of dependence of coefficient Kn on sediment heterogeneity.

Substituting (9), (10), (8) we get the following dependency:

$$
\begin{gathered}
\frac{h_{r}}{d}=-4.38 \cdot e^{0.23 \cdot \varepsilon} \cdot\left(\frac{\vartheta}{\vartheta_{0}}\right)^{2}-\left(9.2 \varepsilon^{2}-35.8 \varepsilon-12.7\right) \cdot \\
\left(\frac{\vartheta}{\vartheta_{0}}-1.1\right)
\end{gathered}
$$

here:

$$
\begin{aligned}
h_{\mathrm{r}}=d\left(-4.38 \cdot e^{0.23 \cdot \varepsilon}\right. & \left(\frac{\vartheta}{\vartheta_{0}}\right)^{2}-\left(9.2 \varepsilon^{2}-35.8 \varepsilon-12.7\right) \cdot \\
& \left.\left(\frac{\vartheta}{\vartheta_{0}}-1.1\right)\right)
\end{aligned}
$$

\subsection{Ridge Shifting Velocity}

Ridge dynamic parameters, i.e. movement velocity is particularly important in designing channel deformation and bedload sediment discharge. Researchers have been studying these characteristics for almost two centuries.

In order to set the connection of ridge movement velocity of various sediment composition with constant mean particle size and mean/scouring flow velocity, from the obtained experimental data we created graphical relationships of $C_{r}=f\left(\vartheta-\vartheta_{0}\right)$ (Figure 9).

Analysis of the graph (Figure 9) shows that with increasing flow rates, the speed of movement of the ridges increases [32]. This pattern was observed by almost all researchers.

The following design formula was obtained on the basis of the analysis of the graphical relationship with accuracy of $0.75 \div 0.9$ :

$$
\mathrm{C}_{r}=\mathrm{K}_{\mathrm{c}} \cdot\left(\vartheta-\vartheta_{0}\right)-\mathrm{K}_{s t}
$$

where: $K_{c}$ - coefficient of proportionality for the i-th composition;

$\mathrm{K}_{\mathrm{st}}$ - ridge breaking factor. 


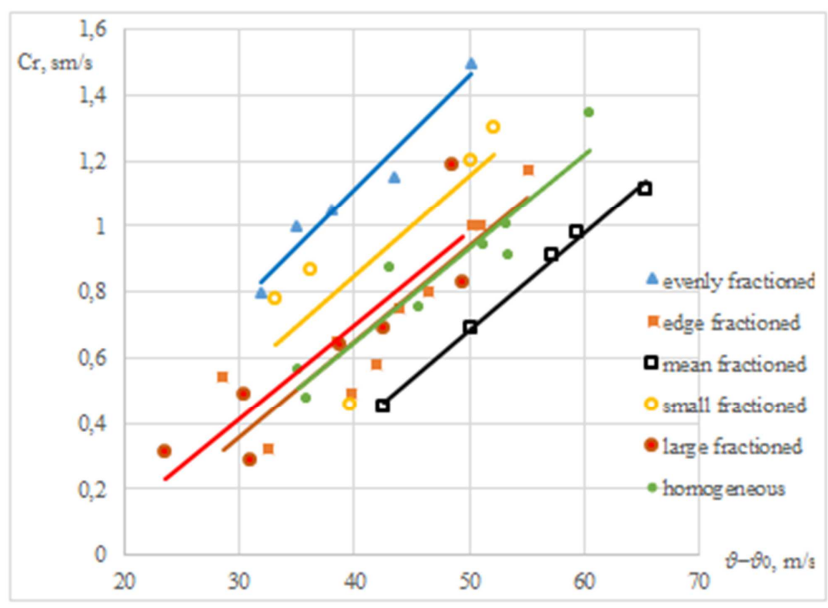

Figure 9. Plot of ridge movement velocity and sediment composition to the scouring flow velocity.

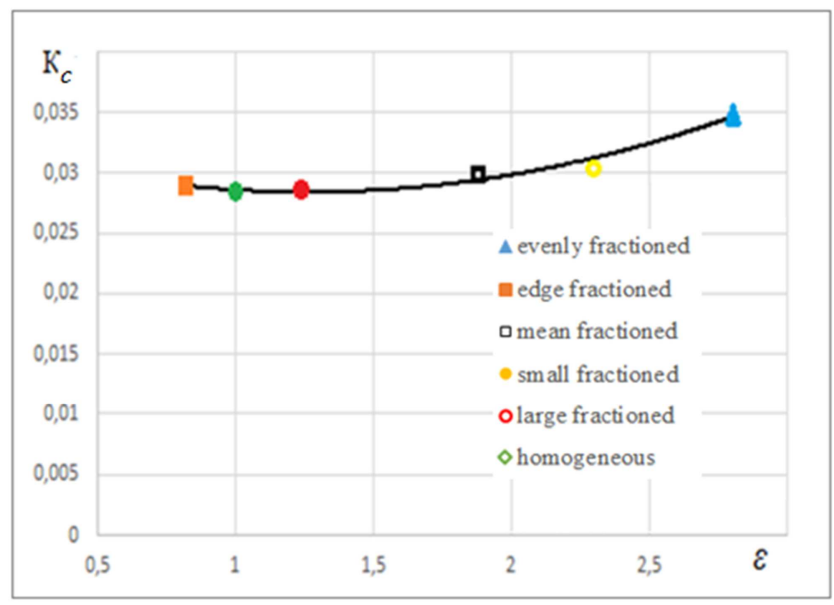

Figure 10. Graph of the coefficient of $K_{c}$ on the heterogeneity of sediment.

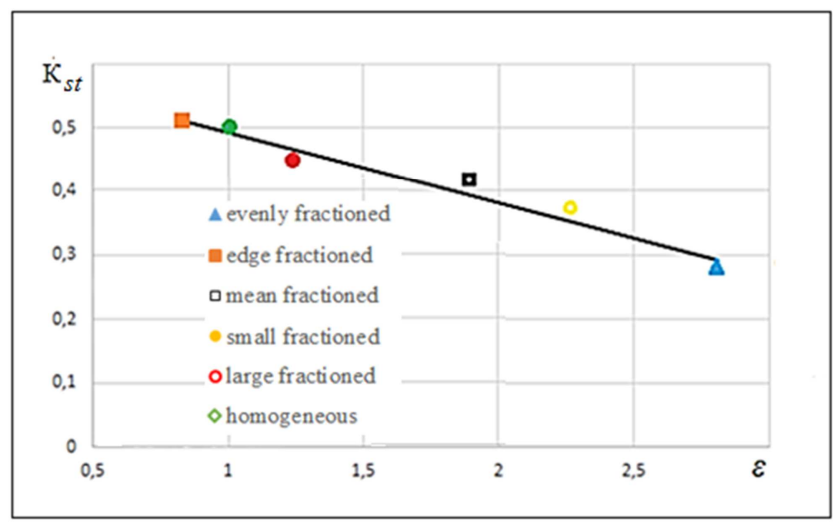

Figure 11. A plot of the displacement coefficient of the ridge $K_{\text {st }}$ on the heterogeneity of sediment.

The proportionality factor for 6 sediment compositions, based on the resulting graphical dependence (Figure 10), is determined by the following formula:

$$
K_{\mathrm{c}}=0.0026 \varepsilon^{2}-0.0066 \varepsilon+0.033
$$

The coefficient of the starting of the ridge, on the basis of the obtained graphical dependence (Figure 11), is determined by the formula:

$$
\mathrm{K}_{s t}=-0.11 \varepsilon^{2}+0.6
$$

Substituting (15), (14), (13) we get the following dependency:

$C_{r}=\left(0.0026 \varepsilon^{2}-0.0066 \varepsilon+0.033\right) \cdot\left(\vartheta-\vartheta_{0}\right)-0.11 \varepsilon^{2}-0.6$

The relationships $(7,12,16)$ obtained from experimental data give more precise determination for ridge length, height and movement velocity change depending on sediment composition heterogeneity of waterways in valley and piedmont regions.

\section{Conclusions}

From the above analysis we can draw that geometric and dynamic bedload ridge characteristics depend on bedload sediment composition. Relationships of heterogeneous bedload sediment ridge length, height, and moving velocity vs. flow relative velocity were obtained. The obtained relationships show that sediment heterogeneity and flow relative velocity change has a direct effect on the bedload ridge form length, height, and its shifting velocity. The increase of the relative flow velocity results in the decrease of ridge length. The increase of the relative flow velocity up to $2.2 \div 2.4$ result in the increase of ridge height at first, then in its decrease. The increase in the difference between mean and scouring flow velocities result in the increase of ridge movement velocity from even to mean fracture composition.

\section{References}

[1] Snischenko, B. F. To the calculation of the length of sand ridges in open streams. Meteorology and Hydrology, 2, 1980, pp. 89-96. (In Russian)

[2] Du Boya P. F. D. Le Rhone et le river a lit affouillable. Annels des Ponts et chaussees, 18 (5), 1879, pp. 141-195.

[3] Diaconu C. Aspecte hidrometrice derivate din particularitatile variatiile debitelor de aluviani in suspensie. Studii de Hidrologie, 30, Bucuresti, 1971, pp. 23-41.

[4] Nielsen, P. and Callaghan, D. P. Shear stress and sediment transport calculations for sheet flow under waves. Coastal Engineering, 47 (3), 2003, pp. 347-354.

[5] Mil-Homens J., Ranasinghe R., Van Thiel de Vries, J. S. M. and Stive, M. J. F. Re-evaluation and improvement of three commonly used bulk longshore sediment transport formulas. Coastal Engineering, 75, 2013, pp. 29-39.

[6] Hale B., Meiburg F., Kneller B. J. Channels formation by turbidity currents: Navier-Stokes-based linear stability analysis. Fluid mechanics, 615, 2008, pp. 185-210.

[7] Bogardi J. Sediment transport in alluvial streams. Academia Kiodo, Budapest, 1974.

[8] Shuai Wang, Bojie Fu, Shilong Piao, Xiaoming Feng, Yafeng Wang. Reduced sediment transport in the Yellow River due to anthropogenic changes. Nature Geoscience, 9, 2016, pp. 38-41. 
[9] Sirdari Z. Z. Bedload transport of small rivers in Malaysia. International Journal of Sediment Research, 29 (4), 2014, pp. 481-490.

[10] Molinas A. and Wu B. Transport of sediment in large sand-bed rivers. Journal of Hydraulic Research, 39 (2), 2001, pp. 135146.

[11] Dean, R. G.; Wells, J. T.; Fernando, H.; Goodwin, P. Sediment Diversions on the Lower Mississippi River: Insight from Simple Analytical Models. Journal Coastal Research, 30, 2013, pp. 13-29.

[12] Alain Recking. Influence of sediment supply on mountain streams bedload transport. Geomorphology, Vs. 175-176, 2012, pp. 139-150.

[13] Fourriere Antoine, Claudin Philippe, Andreotti Bruno. Bed forms in turbulent stream formation of ripples by primary linear instability and of dunes by nonlinear pattern coarsening. Fluid mechanics, 649, 2010, pp. 287-328.

[14] Richardson R. V., Simons D. B. Resistance to flow in sand channels.- Proc. XII Congress of IAHR, Colorado State University. Fort Collins, 1, 1967, pp. 141-150.

[15] Majidov, T. Sh. Calculated hydraulic characteristics of flows and parameters of sand and gravel ridges considering sediment composition. (Doctoral dissertation). Saint Petersburg State Polytechnic University, Russia, 1984. (In Russian).

[16] Seminara G. Fluvial sedimentary patterns. Annual Review of Fluid Mechanics, 42, 2010, pp. 43-66.

[17] Mohd Ekhwan Toriman, Frankie Marcus Ata, Mohd Khairul Amri Kamarudin and Mushrifah Idris. Bed-Load Sediment Profile and Effect of River Bank Erosion on River CrossSection. American Journal of Environmental Science, 9 (4), 2013, pp. 292-300.

[18] Knox, R. I.; Latrubesse, E. M. A geomorphic approach to the analysis of bedload and bed morphology of the Lower Mississippi River near the Old River Control Structure. Geomorphology, 268, 2016, pp. 35-47.

[19] Gilbert G. K., Murphy E. Ch. The transportation of debris by running water. U.S. Geological Survey, Professional Paper 86, 1914.

[20] Kopaliani, Z. D. Calculation of sediment discharge in rivers. Collection of Works on Hydrology. 27, 2004, pp. 25-40. (In Russian).
[21] Kondap, O. M., Garde R. J. Velocity of Bed forms in alluvial channels.- Proc. XV Congress of IAHR, Istambul (Turkey), 5, 1973, pp. 101-103.

[22] Gray, A. B., Pasternack, G. B., Watson, E. B., Warrick, J. A., Goni, M. A. Effects of antecedent hydrologic conditions, time dependence, and climate cycles on the suspended sediment load of the Salinas River, California. Hydrology, 525, 2015, pp. 632-649.

[23] Sahgal P., Singh B. Mechanism of Ripple Formation on Granular Beds. Irrigation and power October, 1973, pp. 387396.

[24] Jalin M. S. Mechanics of sediment transport. Pergamon Press. Oxford, New York, 1972.

[25] Hassan W. N. M. Transport of size-graded and uniform sediments under oscillatory sheet-flow conditions. Dissertation, University of Twenty. PINKSTERRINT, Ensued, The Netherland, 2003.

[26] Bagnold, R. A. An empirical correlation of bedload transport rates in flumes and natural rivers. Proceedings of the Royal Society of London. A. Mathematical and Physical Sciences. 372 (1751), 1980, pp. 453-473.

[27] Hall Philip. Alternating bar instabilities in unsteady channel flows over erodible beds. Mechanics, 499, 2004, pp. 49-73.

[28] Haiyan Yang, Binliang Lin, Jian Sun and Guoxian Huang. Simulating Laboratory Braided Rivers with Bed-Load Sediment Transport. Water, 9 (9), 2017, pp. 686.

[29] Joshi, S.; Xu, J. Y. Resent changes in channel morphology of a highly engineered alluvial river-The Lower Mississippi River. Physical Geography, 2017, pp. 1-26.

[30] Khorram S. and Ergil M. Most influential parameters for the bed load sediment flux equations used in alluvial rivers1. JAWRA Journal of the American Water Resources Association, 46 (6), 2010, pp. 1065-1090.

[31] Marisa C. Palucis, Thomas P. Ulizio, Brian Fuller, Michael P. Lamb. Flow resistance, sediment transport, and bedform development in a steep gravel-bedded river flume. Geomorphology, 320, 2018, pp. 111-126.

[32] Ikramov, N. Effect of bedload sediment heterogeneity on geometric and dynamic characteristics of channel ridge forms. (PhD dissertation). Tashkent Institute of Irrigation and Agricultural Mechanization Engineers, Uzbekistan, 2018. 